\title{
Construction of a bivalent vaccine against anthrax and smallpox using the attenuated vaccinia virus KVAC103
}

Deok Bum Park ${ }^{1,2+}$, Bo-Eun Ahn ${ }^{1 \dagger}$, Hosun Son ${ }^{3}$, Young-Ran Lee ${ }^{1,4}$, Yu-Ri Kim', Su Kyoung Jo', Jeong-Hoon Chun', Jae-Yon Yu', Myung-Min Choi ${ }^{1}$ and Gi-eun Rhie

\begin{abstract}
Background: Anthrax and smallpox are high-risk infectious diseases, and considered as potential agents for bioterrorism. To develop an effective countermeasure for these diseases, we constructed a bivalent vaccine against both anthrax and smallpox by integrating a gene encoding protective antigen (PA) of Bacillus anthracis to the genome of the attenuated vaccinia virus strain, KVAC103.

Results: Immunization with this bivalent vaccine induced antibodies against both PA and vaccinia virus in a mouse model. We also observed that the efficacy of this vaccine can be enhanced by combined immunization with immunoadjuvant-expressing KVAC103. Mouse groups co-immunized with PA-expressing KVAC103 and either interleukin-15 (IL-15) or cholera toxin subunit A (CTA1)-expressing KVAC103 showed increased anti-PA IgG titer and survival rate against $B$. anthracis spore challenge compared to the group immunized with PA-expressing KVAC103 alone.
\end{abstract}

Conclusions: We demonstrated that the attenuated smallpox vaccine KVAC103 is an available platform for a multivalent vaccine and co-immunization of immunoadjuvants can improve vaccine performance.

Keywords: Anthrax, Smallpox, Vaccinia virus, IL-15, Cholera toxin

\section{Background}

Bacillus anthracis and Variola virus are causative agents of anthrax and smallpox, respectively, and representative pathogens that can be possibly utilized as bioterrorism or biological weapons. Development of effective medical countermeasures against these pathogens is a national task of high priority $[1,2]$.

The biological attack in 2001 by B. anthracis spores via the US postal system has prompted the need to develop vaccines and therapeutics against anthrax [1].

\footnotetext{
* Correspondence: gerhie@korea.kr

${ }^{\dagger}$ Deok Bum Park and Bo-Eun Ahn contributed equally to this work. 'Division of High-risk Pathogens, Bureau of Infectious Disease Diagnosis Control, Korea Disease Control and Prevention Agency, Cheongju, South Korea

Full list of author information is available at the end of the article
}

Protective antigen (PA) is one of the major component of anthrax toxin, and also a principal ingredient of two licensed anthrax vaccines, Anthrax Vaccine Adsorbed (AVA) and Anthrax Vaccine Precipitated (AVP) [3]. Recently, a recombinant PA protein vaccine is being developed by Korea Centers for Disease Control (KCDC), and clinical trials are in progress $[4,5]$.

Although endemic smallpox was declared eradicated since the last case observed in 1977, Variolar virus still remains a potential biological weapon [2], and smallpox vaccines have been stockpiled for strategic use in some nations. To reduce side effects of conventional smallpox vaccines, attenuated vaccinia virus strains have been investigated in various ways [6]. KVAC103 is an attenuated vaccinia virus developed by KCDC [7]. 
Interleukin-15 (IL-15) is a cytokine involved in the proliferation and maintenance of $\mathrm{CD}^{+}$memory $\mathrm{T}$ cells, and has been suggested as an effective vaccine adjuvant $[8,9]$. Previous studies on HIV-1 vaccine demonstrated that co-immunization of IL-15 strongly increased antigen-specific memory $\mathrm{T}$ cells and long-term immunity $[10,11]$. Smallpox vaccines with integrated IL-15, tested in a mouse model, showed increased and prolonged cellular and humoral immunity [12]. This IL-15containing smallpox vaccine also has been applied in a multivalent influenza vaccine [13]. Co-administration of IL-15 with staphylococcal enterotoxin B vaccine increased the number of dendritic cells in a mouse model [14].

Cholera toxin (CT) also has long been investigated as an efficient immunoadjuvant. The toxin is composed of subunit $\mathrm{A}$ and $\mathrm{B}$, and subunit A contains two fragments, A1 and A2 [15]. The ADP-ribosyltransferase activity of cholera toxin subunit A1 (CTA1) is known to be important for enhancing immune responses [16]. The effect of CTA1 as an immunoadjuvant has been demonstrated against numerous pathogens, such as influenza A virus, HIV, Helicobacter pylori, and Mycobacterium tuberculosis [17-20].

Vaccinia virus is a popular platform for gene transfer and multivalent vaccine against various diseases [21, 22]. In a previous study, a dual vaccine for smallpox and anthrax has been developed by inserting PA gene of $B$. anthracis into Wyeth or modified vaccinia Ankara (MVA) strain [23]. A viral vector system that utilizes KVAC103 as a gene delivery system and a multivalent vaccine has been previously invented [7, 24]. In this study, we constructed a bivalent vaccine candidate against both smallpox and anthrax, by integrating a recombinant anthrax PA-encoding gene into KVAC103, using a viral vector pVVT1-EGFP-C7L. We examined the protective efficacy of KVAC103-derived bivalent vaccine in a mouse model. In addition, we observed that the vaccine supplemented with immunoadjuvant-expressing vaccinia viruses can increase immune response against anthrax.

\section{Results}

A human codon-optimized PA was cloned into viral vector pVVT1 to generate smallpox/anthrax dual vaccine candidate. A signal peptide derived from the tissue plasminogen activator was attached to the $\mathrm{N}$-terminal of PA (thPA). We also constructed viral vector clones encoding a human IL-15 (hIL15) or a human codon-optimized CTA1 (hCTA1) gene. The viral vectors were integrated into the KVAC103 genome by homologous recombination at the thymidine kinase (TK) gene site (Fig. 1).

Protein expression of PA and CTA1 in the dual vaccine candidate viruses were confirmed by immunoblot assay (Fig. 2)a. PA and CTA1 were detected in virusinfected cell lysates. This indicates that cells infected by KVAC-thPA-C7L or KVAC-hCTA1-C7L viruses properly express PA or CTA1, respectively. The IL-15 ELISA result shows that cells infected by KVAC-hIL15-C7L also secreted IL-15 in vitro (Fig. 2b).

In a preliminary experiment, we observed that repeated vaccination in 3 week interval increased the anti-

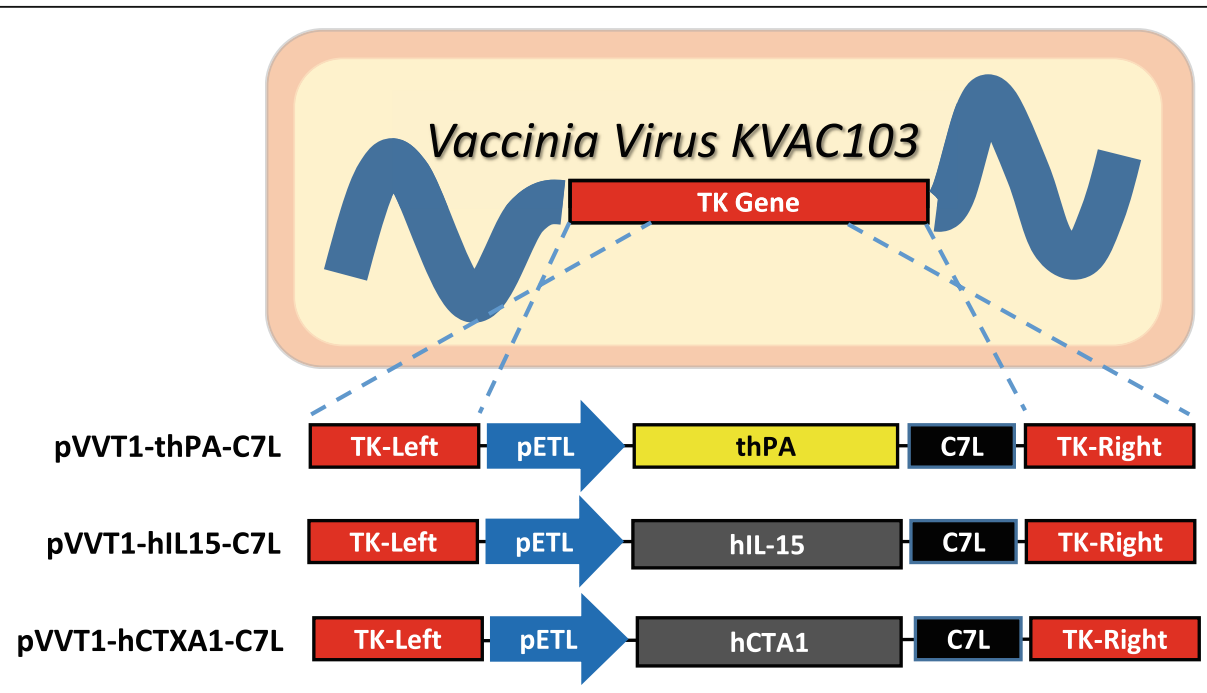

Fig. 1 A diagram of viral vector construction. Human codon-optimized genes encoding PA with a signal peptide (MDAMKRGLCCVLLLCGAVFVSP) derived from the tissue plasminogen activator polypeptide (thPA), IL-15 (hIL15), or CTA1 (hCTA1) were cloned into pWT1-EGFP-C7L. The GeneBank sequence ID for PA, IL-15, and CTA1 are AAA22637.1, NP_000576.1, and CAA24995.1, respectively. The expected molecular weight of integrated thPA, IL-15, and CTA1 are $81 \mathrm{kDa}(757 \mathrm{aa}), 18 \mathrm{kDa}$ (162 aa), and $29 \mathrm{kDa}$ (258 aa), respectively. Viral vector constructs are integrated into KVAC103 genome by homologous recombination at TK gene site 


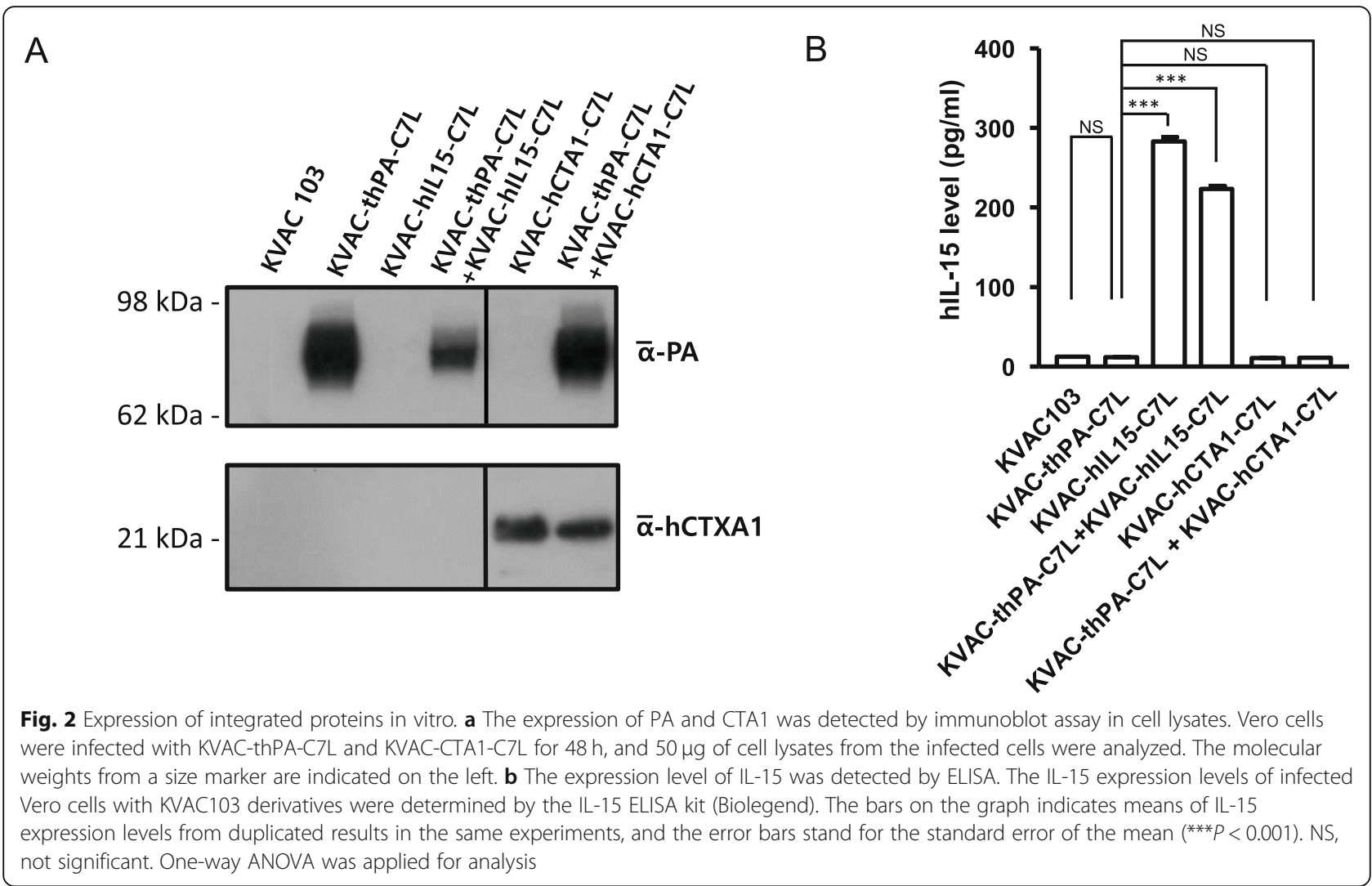

PA antibody titer around 10-fold compared to single vaccination (data not shown). The in vivo efficacy of the dual vaccine candidate with or without adjuvantexpressing viruses was estimated in a mouse model (Fig. 3). We immunized A/J mice $(n=8)$ with our vaccine candidate KVAC-thPA-C7L with or without adjuvant expressing viruses 2 times with a 3-week interval. The anti-PA antibody levels of all groups immunized with KVAC-thPA-C7L were increased compared to the groups immunized with the adjuvant only (KVAChIL15-C7L or KVAC-hCTA1-C7L). Mouse groups vaccinated with KVAC-thPA-C7L plus an immunoadjuvantcontaining strain (KVAC-hIL15-C7L or KVAC-CTA1C7L) exhibited higher mean values of antibody titers compared to the group immunized with KVAC-thPAC7L only (Fig. 3a). Except the two outliers which are extraordinarily high in the group immunized with KVAC-thPA-C7L only in Fig. 3a (29,800 and 30,600), the mean values of anti-PA antibody titer are significantly increased in the mouse groups immunized with both KVAC-tPA-C7L and adjuvant-expressing strains (One-way ANOVA, $p$ value $<0.01$ ).

Neutralizing antibodies against vaccinia virus in mouse sera were measured by PRNT assay. Unlike the anti-PA antibodies, production of neutralizing antibodies against vaccinia virus does not appear to be significantly affected by the presence of immunoadjuvant (Fig. 3b). In a previous study, IL-15 expressing vaccinia virus induced increased neutralizing antibodies compared to the control vaccinia virus in a mouse model [12]. In our experiment, the effect of adjuvants was not observed and all the sera immunized with the constructs induced similar level of neutralizing antibodies.

Immunized mice were challenged with $B$. anthracis Sterne spores 3 weeks after the final vaccination. Survival rates were monitored for 2 weeks. Mice immunized with adjuvant only were all dead within a week. In the group immunized with KVAC-thPA-C7L only, $62.5 \%$ of mice survived, while groups immunized with both KVACthPA-C7L and immunoadjuvant expressing virus (KVAC-hIL15-C7L or KVAC-CTA1-C7L) were fully protected from the challenge (Fig. 3c). The result indicates that enhanced immunity achieved by co-expression of adjuvant can protect the mice more effectively against anthrax.

\section{Discussion}

Poxviruses have been often used as a vector system for vaccines because of their large DNA genome and convenience in manipulation $[21,22]$. In a previous study, engineered vaccinia strains expressing both PA and IL15 showed enhanced immunogenicity against $B$. anthracis compared to the conventional anthrax vaccine AVA in animal test [23]. Our result presented that the co- 
A

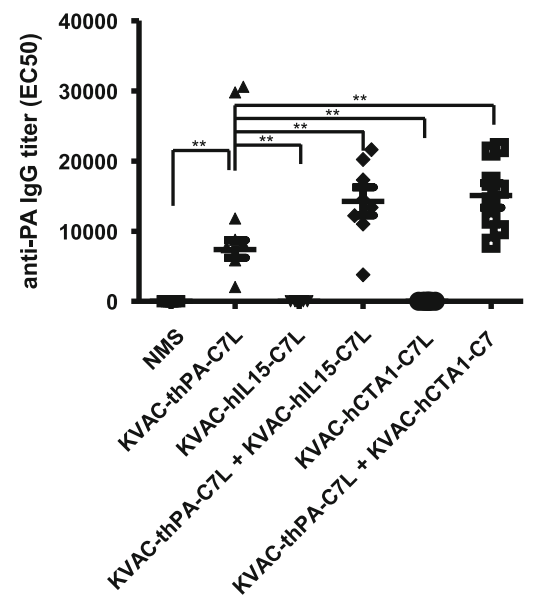

B

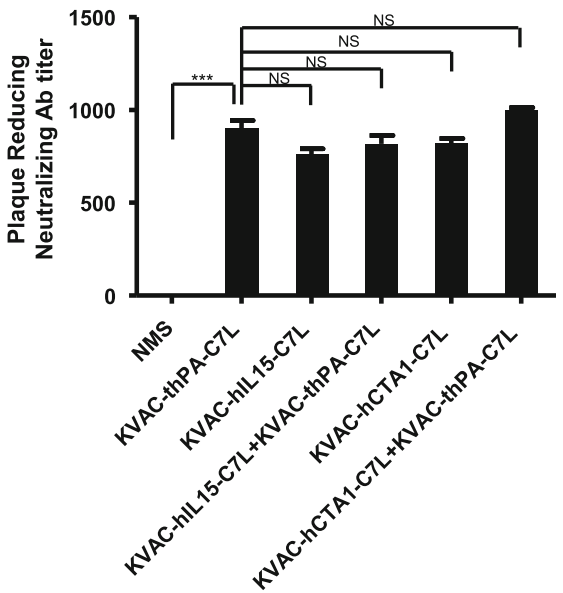

C

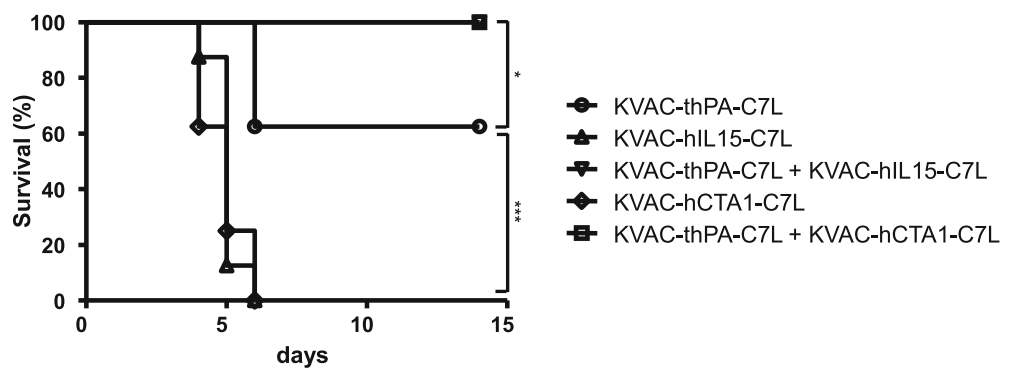

Fig. 3 Immunogenicity and protective efficacy of the bivalent vaccine with or without adjuvant-expressing viruses in a mouse model. a Anti-PA IgG titers of individual mice in 5 groups ( $n=8$ for each group) were determined by ELISA. The $Y$-axis represents $\mathrm{EC}_{50}$ values. The horizontal bars indicate mean of individual groups (for KVAC-thPA-C7L, the mean value calculated except the two outliers). The error bars represent standard error of the mean. The asterisks ${ }^{* *}$ ) represent significant differences between indicated groups in statistical analysis $(* * P<0.01)$. NMS, normal mouse sera. $\mathbf{b}$ Anti-viral antibody titers were determined by PRNT assay. The Y-axis represents PRNT ${ }_{50}$, the reciprocal of the dilution factor of sera reducing plaque formation in half. The bars represent arithmetic means of results from two independent assays with pooled sera of individual groups (eight mice per group) and the error bars represent standard error of the mean (***P<0.001). NS, not significant. NMS, normal mouse sera. c Immunized mice were challenged with $50 \times L_{50}$ of B. anthracis Sterne spores by s.c. injections. Survival rates of 5 groups $(n=8$ for each group) were observed for 14 days. The $p$-value between KVAC-thPA-C7L and KVAC-C7L with immunoadjuvant only (KVAC-hIL-C7L, KVAC-hCTA1C7L) is lower than 0.001 and indicated as ***. The $p$-value between KVAC-thPA-C7L and both KVAC-C7L with PA and immunoadjuvant (KVACthPA-C7L + KVAC-hIL-C7L, KVAC-thPA-C7L + KVAC-hCTA1-C7L) is lower than 0.05 and indicated as *

expression of IL-15 in KVAC103 also enhanced protective efficacy of our bivalent vaccine. Co-expression of CTA1 induced immune response against the PAexpressing vaccine in the similar level to IL-15. Our result demonstrated that co-immunization of CTA1, as well as IL-15, was effective enough to enhance the immune responses against PA and reconfirmed that CTA1 is a suitable adjuvant for multivalent vaccines derived from KVAC103. This result is the first observation of the effect of CTA1 as an immunoadjuvant in a viral vaccine system.

\section{Conclusion}

In summary, we explored the possibility of developing a bivalent vaccine using KVAC103, an attenuated vaccinia virus strain. Like other vaccinia virus strains previously utilized, it is confirmed that KVAC103 also can serve as a useful platform for multivalent vaccines. In addition, the vaccine can be further effective with the supplement of cytokines or adjuvants.

\section{Methods}

\section{Cell and virus}

Vero cell (African green monkey kidney cell) was purchased from the American Type Culture Collection (ATCC, USA). Cells were grown in Opti-Eagle's Minimum Essential Medium (Opti-MEM, Invitrogen) supplemented with $2 \%$ heat-inactivated fetal bovine serum (FBS, Invitrogen), incubated at $37^{\circ} \mathrm{C}$, and humidified with $5 \% \mathrm{CO}_{2}$. The attenuated vaccinia virus strain KVAC103 and the viral vector pVVT1-EGFP-C7L were provided by Korea National Institute of Health (KNIH). 
This vector contains the vaccine virus $\mathrm{C7L}$ gene which encodes interferon antagonist, and this is one of the 26 genes defective in KVAC103 compared to its ancestor strain. This gene is required for enhanced viral reproduction [24].

\section{Construction of anthrax/smallpox dual vaccine candidate vectors}

Viral vector constructs were generated using the pVVT1-EGFP-C7L vector [24] as a template (Fig. 1). Human IL-15 gene and human codon-optimized $B$. anthracis PA and CTA1 genes were synthesized (Bioneer). The synthesized genes were cloned into the vector using SfiI restriction enzyme site. The constructed vectors were mixed with Lipofectamine (Invitrogen) and transfected into KVAC103-infected Vero cells. Single plaques were isolated from the original infected cells and verified using PCR. The primer sequences used for verification were 5' -TTT GAA GCA TTG GAA GCA ACT3 ' and '5'-ACG TTG AAA TGT CCC ATC GAG T-3'.

\section{Virus preparation}

Viruses were infected to mono-layered Vero cells with $0.01 \mathrm{MOI}$. The virus-infected cell media were harvested when more than $80 \%$ of total cells showed cytopathic effect. From the harvested culture supernatant, viruses were collected by ultra-centrifugation. The pellet was resuspended in $1 \times$ PBS, pH 7.0 (Gibco). The concentration of viral particles was determined by the standard plaque assay. The viruses were infected the Vero cells overlaid on 6-well plates for 2 days. The plate were staining with crystal violet and the plaque numbers on each well were counted.

\section{Western blot analysis}

Virus-infected Vero cells or their culture supernatants were lysed in $1 \times$ RIPA buffer (G-Bioscience) containing $1 \%$ PMSF (Theromfisher Scientific) at $4{ }^{\circ} \mathrm{C}$. Fifty $\mu \mathrm{g}$ of protein from each cell lysate was resolved on denaturing polyacrylamide gel electrophoresis (PAGE) and transferred to polyvinylidene difluoride (PVDF) membrane (Amersham). Expression levels of PA and CTA1 proteins were detected using mouse monoclonal antibodies against PA and cholera toxin, respectively (Abcam, 1: 1000), and horse radish peroxide (HRP)-conjugated secondary antibodies (Abcam, 1:3000).

\section{Mouse immunization and serum collection}

Female A/J mice (5-week old) were purchased from SLC, Inc. (Japan) and housed in an animal biosafety level 2 (ABL2) facility in KCDC. Mice were immunized with the vaccine candidate virus $\left(5 \times 10^{7} \mathrm{pfu} /\right.$ mouse $)$ with or without the adjuvant-expressing virus $\left(5 \times 10^{7} \mathrm{pfu} /\right.$ mouse) 2 -times at 3 -week intervals subcutaneously (s.c.) with 8 mice as a group. Mice sera were collected 20 days after final immunization to measure anti-PA IgG and vaccinia virus plaque reduction neutralizing antibody titers. The schematic view of mouse immunization and serum collection is in Fig. 4.

\section{Enzyme-linked immunosorbent assay (ELISA)}

The anti-PA IgG titers of mice sera were determined by ELISA as previously described with some modifications [25]. Briefly, 96 well plates were coated with $1 \mu \mathrm{g} / \mathrm{ml}$ of recombinant PA (Green Cross, Korea). Mouse sera were diluted from 1:100 to 1:204800 and loaded to each well, incubated for $1 \mathrm{~h}$ at $37^{\circ} \mathrm{C}$. Horseradish peroxidaseconjugated anti-mouse IgG goat antibody (Invitrogen) and 3,3 $, 5,5^{`}$-tetramethylbenzidine (TMB) substrate were used for detection. The optical density of each well was measured at $450 \mathrm{~nm}$ and the half maximal effective concentration $\left(\mathrm{EC}_{50}\right)$ was calculated by 4-parameter logistic equation regression using SoftMaxPro5.3 (Molecular Device, USA). The data were analyzed and visualized using GraphPad Prism 5.

The IL-15 expression level of KVAC103 derivatives were determined by the IL-15 ELISA kit (Biolegend) according to the manufacturer's protocol. Vero cells were infected with viruses of 0.01 MOI. Cell lysates were collected 2 days after infection and analyzed.

\section{Plaque reduction neutralization test (PRNT)}

Serial two-fold dilutions of heat-inactivated mouse sera were mixed with vaccinia virus Lister strain of approximately 50 plaque forming units (PFU). After $2 \mathrm{~h}$

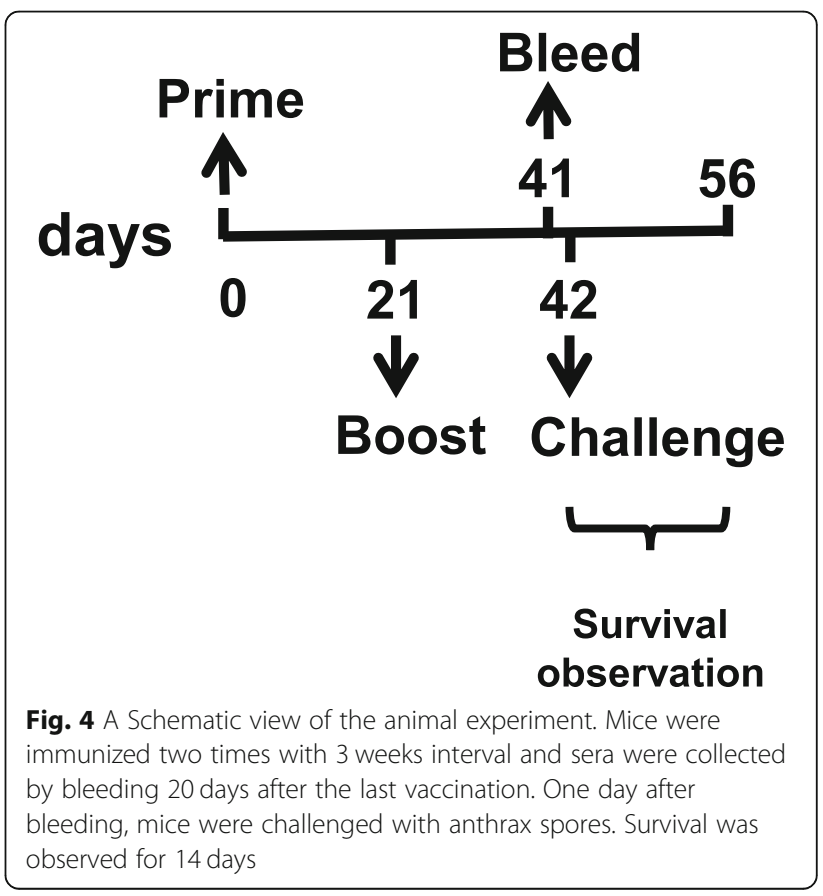


incubation at $37^{\circ} \mathrm{C}$, the serum and virus mixtures were inoculated onto monolayered Vero cells. After two days incubation at $37^{\circ} \mathrm{C}$ with $5 \% \mathrm{CO}_{2}$, cells were fixed and stained using a mixture of crystal violet and formalin for $10 \mathrm{~min}$. Stained plates were dried in air at room temperature and the plaque numbers were counted. The neutralizing antibody titer was defined as the reciprocal of dilution factor that reduced plaque numbers in half (50\%) compared to a serum-free control $\left(\mathrm{PRNT}_{50}\right)$.

\section{B. anthracis spore challenge}

Immunized mice were challenged with 50 -fold of lethal dose $50\left(\mathrm{LD}_{50}\right)$ of $B$. anthracis Sterne spore by s.c. injections. Survival of the mice was monitored for 14 days as described in Fig. 4. Spores were prepared according to a previous study [26]. The $\mathrm{LD}_{50}$ determined by ReedMuench method [27] in A/J mice model via s.c. route was 1794 spores. Survived animals were euthanized using $\mathrm{CO}_{2}$ gas. Animal study protocols (KCDC-102-16$2 \mathrm{~A}$ and KCDC-039-17-2A) were approved by the Institutional Animal Care and Use Committee (IACUC) of Korea Centers for Disease Control and Prevention (KCDC). All procedures involved in the housing and care of animal strictly followed guidelines and requirements of the IACUC.

\section{Statistical analysis}

The Statistical analysis was performed using GraphPad Prism 5. To analyze the anti-PA ELISA titer, One-way ANOVA followed by Tukey's post hoc test were used to evaluate the difference between groups. To analyze the survival rate, Kaplan-Meier survival plots were evaluated with the log-rank test.

\section{Supplementary Information}

The online version contains supplementary material available at https://doi. org/10.1186/s12866-021-02121-5

\section{Additional file 1 \\ Additional file 2 \\ Additional file 3}

\section{Acknowledgements}

Not applicable.

\section{Authors' contributions}

Experiments were performed by DBP, HSS, YRL, YRK, and SKJ. Data analysis were performed by DBP and BEA. The study was supervised by JHC, JYY, MMC, and GER. The original draft was written by BEA and DBP. The manuscript was reviewed and edited by BEA and GER. The authors read and approved the final manuscript.

\section{Funding}

This research was supported by Research of Korea Centers for Disease Control and Prevention (project numbers; 2016-NG45002-00, 2017NG45002-00 and 4840-302-210-13).
Availability of data and materials

The datasets used and/or analyzed during the current study are available from the corresponding author on reasonable request.

Ethics approval and consent to participate

Animal study protocols were approved by the Institutional Animal Care and Use Committee (IACUC) of Korea Centers for Disease Control and Prevention (KCDC). All experimental procedures were approved by Institutional Review Board (IRB) of KCDC

Consent for publication

Not applicable.

\section{Competing interests}

The authors declare that they have no competing interests.

\section{Author details}

${ }^{1}$ Division of High-risk Pathogens, Bureau of Infectious Disease Diagnosis Control, Korea Disease Control and Prevention Agency, Cheongju, South Korea. ${ }^{2}$ Present address: Forensic DNA Division, Gwangju Institute, National Forensic Service, Jeonnam, South Korea. ${ }^{3}$ Division of Vaccine Research, Korea National Institute of Health, Korea Centers for Disease Control and Prevention, Cheongju, South Korea. ${ }^{4}$ Present address: Convergence Bioceramic Materials Center, Korea Institute of Ceramic Engineering and Technology, Cheongju, South Korea.

Received: 31 August 2020 Accepted: 9 February 2021

Published online: 08 March 2021

References

1. Russell PK. Project BioShield: What It Is, Why It is Needed, and Its Accomplishments So Far. Clin Infect Dis. 2007;45(Supplement_1):S68-72.

2. Cieslak TJ, Christopher GW, Kortepeter MG, Rowe JR, Pavlin JA, Culpepper RC, Eitzen EM Jr. Immunization against potential biological warfare agents. Clin Infect Dis. 2000;30(6):843-50.

3. Cybulski RJ Jr, Sanz P, O'Brien AD. Anthrax vaccination strategies. Mol Asp Med. 2009;30(6):490-502

4. Rhie GE, Park YM, Chun JH, Yoo CK, Seong WK, Oh HB. Expression and secretion of the protective antigen of Bacillus anthracis in Bacillus brevis. FEMS Immunol Med Microbiol. 2005;45(2):331-9.

5. Kang CK, Kim NH, Kim CJ, Rhie GE, Jo SK, Ahn M, Kang J, Choe PG, Park WB, Kim NJ, et al. Immunogenicity and safety of a novel recombinant protective antigen anthrax vaccine (GC1109), a randomized, single-blind, placebo controlled phase II clinical study. Vaccine. 2019;37:3820-4.

6. Kennedy RB, Lane JM, Henderson DA, Poland GA. 54 - Smallpox and Vaccinia. In: Plotkin SA, Orenstein WA, Offit PA, Edwards KM, editors. Plotkin's Vaccines (Seventh Edition): Elsevier; 2018. p. 1001-30. e1012. https://doi.org/10.1016/B978-0-323-35761-6.00054-7. https://www. sciencedirect.com/science/article/pii/B9780323357616000547.

7. Lee YJ, Son HS, Yeo SG, Yoo JS, Lee SW. Development of viral vector using attenuated Vaccinia virus strain, KVAC103. Public Health Weekly Report, KCDC. 2016:9(38):755-9.

8. Tovey MG, Lallemand C. Adjuvant activity of cytokines. Methods Mol Biol. 2010:626:287-309

9. Perera PY, Lichy JH, Waldmann TA, Perera LP. The role of interleukin-15 in inflammation and immune responses to infection: implications for its therapeutic use. Microbes Infect. 2012;14(3):247-61.

10. Calarota SA, Dai A, Trocio JN, Weiner DB, Lori F, Lisziewicz J. IL-15 as memory T-cell adjuvant for topical HIV-1 DermaVir vaccine. Vaccine. 2008; 26(40):5188-95.

11. Oh S, Berzofsky JA, Burke DS, Waldmann TA, Perera LP. Coadministration of HIV vaccine vectors with vaccinia viruses expressing IL-15 but not IL-2 induces long-lasting cellular immunity. Proc Natl Acad Sci U S A. 2003; 100(6):3392-7.

12. Perera LP, Waldmann TA, Mosca JD, Baldwin N, Berzofsky JA, Oh S. Development of smallpox vaccine candidates with integrated interleukin-15 that demonstrate superior immunogenicity, efficacy, and safety in mice. J Virol. 2007;81(16):8774-83.

13. Valkenburg SA, Li OT, Mak PW, Mok CK, Nicholls JM, Guan Y, Waldmann TA Peiris JS, Perera LP, Poon LL. IL-15 adjuvanted multivalent vaccinia-based 
universal influenza vaccine requires CD4+ T cells for heterosubtypic protection. Proc Natl Acad Sci U S A. 2014;111(15):5676-81.

14. Saikh KU, Kissner TL, Nystrom S, Ruthel G, Ulrich RG. Interleukin-15 increases vaccine efficacy through a mechanism linked to dendritic cell maturation and enhanced antibody titers. Clin Vaccine Immunol. 2008;15(1):131-7.

15. Agren L, Lowenadler B, Lycke N. A novel concept in mucosal adjuvanticity: the CTA1-DD adjuvant is a B cell-targeted fusion protein that incorporates the enzymatically active cholera toxin A1 subunit. Immunol Cell Biol. 1998: 76(3):280-7.

16. Agren LC, Ekman L, Lowenadler B, Nedrud JG, Lycke NY. Adjuvanticity of the cholera toxin A1-based gene fusion protein, CTA1-DD, is critically dependent on the ADP-ribosyltransferase and Ig-binding activity. J Immunol. 1999;162(4):2432-40.

17. Eliasson DG, El Bakkouri K, Schon K, Ramne A, Festjens E, Lowenadler B, Fiers W, Saelens X, Lycke N. CTA1-M2e-DD: a novel mucosal adjuvant targeted influenza vaccine. Vaccine. 2008;26(9):1243-52.

18. Sundling C, Schon K, Morner A, Forsell MNE, Wyatt RT, Thorstensson R, Hedestam GBK, Lycke NY. CTA1-DD adjuvant promotes strong immunity against human immunodeficiency virus type 1 envelope glycoproteins following mucosal immunization. J Gen Virol. 2008;89(Pt 12):2954-64.

19. Akhiani AA, Stensson A, Schon K, Lycke N. The nontoxic CTA1-DD adjuvant enhances protective immunity against helicobacter pylori infection following mucosal immunization. Scand J Immunol. 2006;63(2):97-105

20. Andersen CS, Dietrich J, Agger EM, Lycke NY, Lovgren K, Andersen P. The combined CTA1-DD/ISCOMs vector is an effective intranasal adjuvant for boosting prior Mycobacterium bovis BCG immunity to Mycobacterium tuberculosis. Infect Immun. 2007;75(1):408-16.

21. Altenburg AF, Kreijtz JH, de Vries RD, Song F, Fux R, Rimmelzwaan GF, Sutter $G$, Volz A. Modified vaccinia virus Ankara (MVA) as production platform for vaccines against influenza and other viral respiratory diseases. Viruses. 2014; 6(7):2735-61.

22. Gomez CE, Najera JL, Krupa M, Esteban M. The poxvirus vectors MVA and NYVAC as gene delivery systems for vaccination against infectious diseases and cancer. Curr Gene Ther. 2008;8(2):97-120.

23. Merkel TJ, Perera PY, Kelly VK, Verma A, Llewellyn ZN, Waldmann TA, Mosca $J D$, Perera LP. Development of a highly efficacious vaccinia-based dual vaccine against smallpox and anthrax, two important bioterror entities. Proc Natl Acad Sci U S A. 2010;107(42):18091-6.

24. Son HS, Yeo SG, Lee SW: Recombinant Vaccinia Virus Derived From Kvac103 Strain. In. US patent 9,879,281: Korea centers for disease control and prevention; 2016.

25. Chun JH, Choi OJ, Cho MH, Hong KJ, Seong WK, Oh HB, Rhie GE. Serological correlate of protection in Guinea pigs for a recombinant protective antigen Anthrax vaccine produced from Bacillus brevis. Osong Public Health Res Perspect. 2012;3(3):170-6

26. Ivins B, Fellows P, Pitt L, Estep J, Farchaus J, Friedlander A, Gibbs P. Experimental anthrax vaccines: efficacy of adjuvants combined with protective antigen against an aerosol Bacillus anthracis spore challenge in Guinea pigs. Vaccine. 1995;13(18):1779-84.

27. Reed $\sqcup$, Muench $\mathrm{H}$. A simple method of estimating fifty per cent endpointS12. Am J Epidemiol. 1938;27(3):493-7.

\section{Publisher's Note}

Springer Nature remains neutral with regard to jurisdictional claims in published maps and institutional affiliations.

Ready to submit your research? Choose BMC and benefit from:

- fast, convenient online submission

- thorough peer review by experienced researchers in your field

- rapid publication on acceptance

- support for research data, including large and complex data types

- gold Open Access which fosters wider collaboration and increased citations

- maximum visibility for your research: over $100 \mathrm{M}$ website views per year

At $\mathrm{BMC}$, research is always in progress.

Learn more biomedcentral.com/submissions 